\title{
Generic Structural Features of Requestive Academic Emails
}

\author{
Imen Aribi Ben Amor \\ Higher Institute of Languages of Gabes, Tunisia, City Riadh Zerig 6029 Gabes, Tunisia
}

\begin{abstract}
The aim of the present study is to analyze the generic structural features of requestive academic emails. For this purpose, 182 emails written by 81 Tunisian postgraduate students to their professor were analysed. The collected academic email messages share a main communicative function which is requesting. This study drew on the framework of genre analysis and employed the pattern of move schemata proposed by Swales (1990) and follows the typology suggested by Guffey (2010). The gathered emails are made up of the email's subject line, an opening, body text and closing. The findings revealed that more than half of the subject lines of emails are either inappropriate, improper or do not exist. This shows that the participants are to some extent not able to write proper subject lines when addressing their professor however they did appear to pay attention to greetings in their emails. By examining the structure of the body of the gathered emails, it is noticed that postgraduate students tended to use the inductive style when emailing their professor. They do not go straight to the request. Instead, they go through some strategies (introduction, self-identification, apologizing, or reminding remarks, pre-request and request). The findings revealed that more than half of the emails either do not display perfect closings or do not display closings while the remaining emails are considered acceptable since they contain both greeting and the sender's name. Accordingly, this study suggests some useful pedagogical implications. Tunisian EFL learners need to be supplemented with explicit instruction regarding teaching pragmatic issues concerning writing emails. The use of authentic materials in the context of pragmatics instruction is highly recommended Another practical method is to introduce and teach email writing guidelines and etiquettes so that Tunisian students can readily refer to them when writing emails.
\end{abstract}

Keywords: structural features, request, email, moves.

DOI: $10.7176 / \mathrm{JEP} / 10-19-03$

Publication date:July $31^{\text {st }} 2019$

\section{Introduction}

Technological advances in information and communication technology have led to increased use of online communication including email (electronic mail), which falls under the broad category of computer-mediated communication (CMC). Emails facilitate communication between people wherever they are. Email has been widely adopted for both personal and institutional communication because of its high transmission speed (Crystal, 2001). Email has become a tool of mass global communication with the advantages of simplicity, speedy delivery, ease of communication, cost effectiveness, geographical independence, and the portability of mailboxes (Lan, 2000; Gupta et al., 2004). Indeed, a massive amount of email messages is sent out every day around the world. Since it is considered as a relatively recent development, email is not yet governed by clear conventions and netiquettes (Herring, 2001). Indeed, the fact that email is a medium of communication that is situated somewhere along the continuum between spoken and written communication may be behind that. Academic studies of CMC suggest that email combines features of spoken and written language (Georgakopoulou, 2003, p. 94). On the one hand, email is characterized by an informal style, limited planning and editing and fast feedback (Herring, 2001).

On the other hand, it contains features such as lack of visual and pragmatic clues, written format, and the physical absence of the interlocutors, which characterize written modes of communication (ibid). Email often contains non-standard features, abbreviations, typos and mixed case, and as such, it presents particular competency challenges for its users (ibid). With its hybrid form, various discourse strategies that have been employed in oral and written communication are manifested in email communication as well (Gains, 1999; Herring, 1996). As far as the academic setting is concerned, although most student-professor interaction occurs during office hours, in class, before and after class, and perhaps on the phone, email has become a viable alternative means of communication, providing the convenience of obtaining clarification, feedback, and permission almost instantly when students need it (Biesenbach-Lucas, 2007). Email is becoming an accepted means of communication between university students and their professors (Biesenbach-Lucas, 2007). Thus, the use of emails has become a necessary part of students' academic interaction, becoming more common than the student-teacher office hour meeting (Biesenbach-Lucas, 2006, p.81). In fact, one of the main functions of student-to-teacher email is requests, asking for help or information (Bloch, 2002; Martin et al., 1999).

Despite the widespread use of email on university campuses, norms and conventions for appropriate academic emails are not yet fully established or at least are recognized differently by students and faculty (Shim, 2013). Because its conventions are not clearly specified, and because it borders on oral and written 
communication styles, email is a mode of communication that can pose particular challenges for its users, especially if it has to be composed in a foreign language. Among the advantages of email is that it is asynchronous and receivers can reply to the messages at their own time and pace. However, as a medium that lacks linguistic cues, the email is subject to recipient's interpretation and can possibly lead to miscommunication (Biesenback-Lucas, 2007). It is hardly surprising, therefore, that many students, native (NS) and nonnative speakers (NNS) alike, struggle with the genre (Bloch, 2002; Chen, 2001, 2006; Epstein, 2006; Glater, 2006; Hartford and Bardovi-Harlig, 1996). Both NS and NNS are often faced with uncertainties regarding the style and politeness strategies in email interaction (Crystal, 2001; Barron, 2002, 2003; Biesenbach Lucas, 2006) especially in hierarchical relationships where the power asymmetry needs to be maintained. This is particularly the case in student-faculty email interaction (Economidou-Kogetsidis, 2011).

While people can write emails to peers in any manner they like, writing emails to authority figures requires high pragmatic competence and critical language awareness of how discourse shapes and reflects power asymmetry in an instituational context (Chen, 2006). Email writers' ambivalence and uncertainty about how to encode communicative intent in this text-only medium tend to surface especially in hierarchical relationships and in situations involving impositions on the addressee (Biesenbach-Lucas, 2007). Although writing email requests to lecturers has become a necessary part of academic life for most students, it is found to be a difficult undertaking. Hence, many studies focus on emails in order to unveil their structural features,genres, style, and form, as well as pragmatic functions. This study focuses on examining a corpus of requestive emails written by a group of Tunisian postgraduate students to their professor and seeks to unveil their generic structural features. This article is organized as follows. The next section provides theoretical background on linguistic research studies on emails and sheds light on the different features studied. This is followed by a description of the methods and procedures followed in the present study. After that the findings are described and discussed and interpreted. The last part presents the conclusion and suggests some implications.

\section{Literature review}

Each genre of discourse has its distinctive structural features, which includes all those elements such as length, appearance, layout, orthographic conventions, graphics, etc. Since the early days of email, researchers realized that this new medium of communication had new conventions that did not fully belong to spoken or written varieties of language (Foutouhi and Ziayei, 2015). It is argued that the email was a fundamentally new medium with significantly new characteristics that cannot be treated with the old rules alone (Foutouhi and Ziayei, 2015). Shapiro and Anderson (1985, p. 10) point out that email is 'a fundamentally new medium with significantly new characteristics that cannot be treated with the old rules alone'. Although email messages have several features in common with letter writing which belong to the same family of texts (Al-Khatib, 2001), they differ in a considerable number of other features (Al-Khatib, 2008). Thus, many researchers have tried to look for the distinctive features of emails. Gains' (1999) genre-analytical study of emails produced by English native speakers found that the search for common features for stylistic register proved to be problematic due to the extremely wide diversity of registers adopted by the writers of emails (1998, p. 92).

Gains (1999) examined 116 messages sent within a British insurance company and 54 mails received by four British academics. After exploring the characteristics of the messages, Gains (1999) concluded that commercial emails were largely consistent with standard business letters whereas academic emails showed a pseudo-conversational form of communication though conducted in extended time and with an absent interlocutor. As for the structural features of email messages, Al-Khatib (2008) suggests two types of features: obligatory and optional. The obligatory are those features that should be included in the text such as the heading, short introduction, substance of the message, conclusion of good wishes and the sender's name; and the optional ones are those that are left to personal choice such as emoticons (ibid). In studying student emails, EconomidouKogetsidis (2011) asserts that some of these emails are more conversational and informal while others follow a more business template and might include an opening, a closing, a salutation, more formal vocabulary, etc.

Biesenbach-Lucas (2007) asserts that emails at the university setting were found to be characterized by 'more casual language, truncated syntax, abbreviations, and symbols'. Wei-Hong Ko et al., (2015) notes that email communication is composed of various other components such as opening, small talk and closing, which, if utilized properly, have the potential to mitigate the perceived face threat of request messages. Other researchers paid attention to such matters as how email writers place their requests in their emails. Halpern (1985) calls for placing requests at the very begining of the message while Hawisher and Moran (1993) recommend placing it at the end. However, Lea (1991) notes that email users often write fast and spontaneously without paying attention to where to place the most important points in emails.

On the other hand, Lund (1998) analyses the rhetorical differences between traditional academic writing and email texts. He found that the participants' writing style of emails written to their teachers is different from those written to their peers. Students' writing to their teacher involves an absence of their own voice. Their writing was impersonal in contrast with the writing of those letters sent to peer students using first person to 
make an interpersonal relation (ibid).

Chen (2006) carried out a longitudinal case study of a Taiwanese graduate student's email practice in English during her studies at a U.S. university for two and a half years. Chen (2006) notices that the Taiwanese student usually started a message with a self-identification statement (e.g. "This is Ling. I'm in your xxx class.") followed by an abstract or pre-request without giving a specific purpose (e.g., "I need help from you" or "I have some questions I need to ask you"). Then she provided lengthy personal details or contextual information explaining why she needed to make the request, and finally she placed her request act or purpose statement (e.g. "I want to ask you to write a recommendation for me") at the end of the message (ibid). This inductive structure was an important discourse feature that remained unchanged in the student's long-term email communication with both peers and professors. From Ling's (the student) perspective, she chose this inductive structure intentionally for the sake of indirectness.

Al-Ali and Sahawneh (2008) have looked at requestive email messages written by native (Americans) and non-native speakers of English (Jordanian) addressed to the same reader. It is found that both groups utilize some similar generic components such as 'Opening', identifying self', 'Apologizing', 'Requesting', Ending politely', and 'Closing', however each group uses certain moves that are very rare or do not even exist in the other group's texts. For example, the American native speakers tend to use other moves such as 'Referring to documents', and 'Specifying means of further communication' while Jordanian nonnative speakers utilize certain moves like 'Invoking compassion' that does not surface in the native speakers' texts. While many studies analyzed the language of emails or has looked for evidence of socio-pragmatic norms that govern email, to the best of the researcher's knowledge, few studies focused on analyzing the generic structural features of requestive academic emails. Therefore, the current study is an attempt to analyze the generic structural and registerial features of academic email messages. The study also aims to shed light on the nature of the discursive strategies used by Tunisian postgraduate students

\section{Method}

The corpus of the present study consists of 182 emails written by 81 Tunisian postgraduate students enrolled in several institutions in Tunisia to their professor. The data were collected from the inbox of the researcher's supervisor. The emails were naturally or spontaneously generated, that is, they are naturally occurring discourse as opposed to elicited discursive data. The writers of the emails are 81 Tunisian postgraduate students of English, 67 of whom are female and 14 are male. All of these students knew the professor personally. The participants are supposed to be advanced at the level of language proficiency because all of them had studied English for at least 3 years in BA (Bachelor of Art) before enrolling in postgraduate programs. The collected academic email messages share a main communicative function which is requesting. These requests are either requests for information or requests for action for the benefit of the requester. According to Swales (1990) and Bhatia, (1993), the users of any genre share some sets of communicative purposes realized by a schematic structural component moves in a particular context. The current study drew on the framework of genre analysis and employed the pattern of move schemata proposed by Swales (1990) to examine the academic email requests for specific generic features and their linguistic realizations. The analysis of generic structural features of the present corpus also follows the typology suggested by Guffey (2010).

In explaining email message components, Guffey (2010) suggested four parts:

a) An informative subject line, b) an opening, c) a body and d) an appropriate closing.

Drawing on Swales' (1990) and Guffey (2010) models, the coprus is analyzed, and the obligatory and optional moves as well as their frequencies and sequences are identified. The qualitative analysis of the corpus is carefully undertaken to identify the strategies that realize each move with modifications and additions of certain moves. The frequency of occurrence of each strategy is calculated too. Then, the researcher provides contextual explanations why these rhetorical options and stylistic choices were utilized by the participants to achieve their communicative purpose.

\section{Findings and discussion}

The first component in emails is the heading, which automatically appears at the top of all emails. It consists of four titles: "from", "to", "date", and "subject" which include the sender's address, the receiver's address, the date of sending, and the topic of the letter, respectively (Guffey, 2010). Previous studies such as Guffey (2010) point out that the discourse structure of emails is composed of the email's subject line, an opening (salutations and alerters), body text and closing remarks as it is shown in the following figure. 


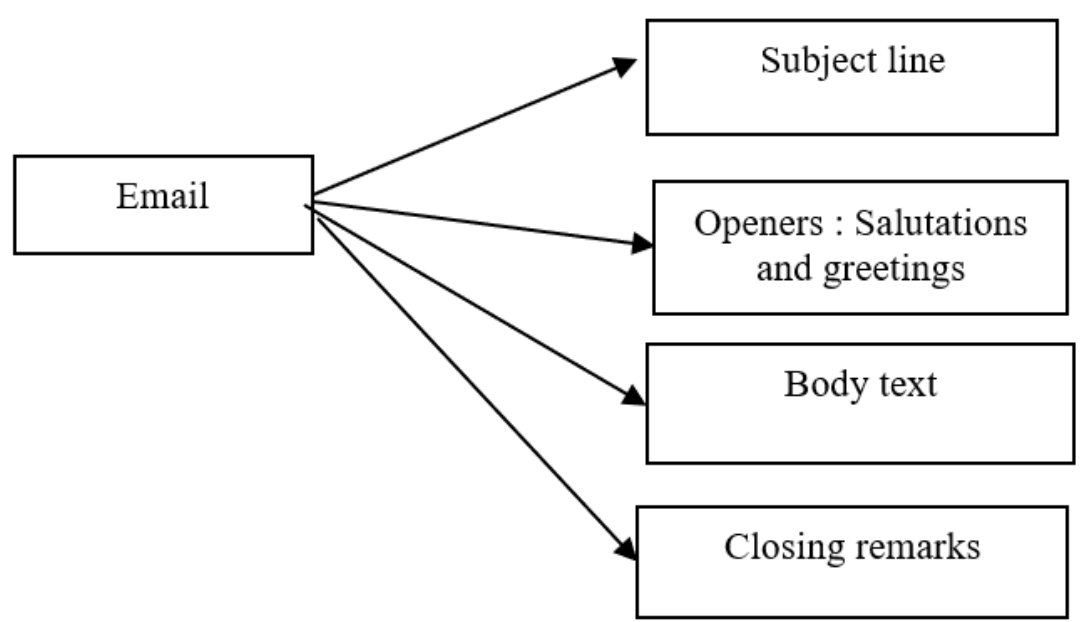

Figure 1. Guffey's (2010) email discourse structure

Al-Khatib (2001) distinguishes the obligatory components( which are those features that should be included in the text such as the heading, short introduction, substance of the message, conclusion of good wishes and the sender's name) from the optional ones which are those that are left to personal choice such as emoticons. Thus, email writers should keep within the discourse tradition of the genre in order to provide well-elaborated emails and achieve their communicative goals. As it is indicated from the figure above, the first component of the email discourse structure is the subject line.

\subsection{Subject line.}

In any email, the first textual element is the subject line, which is usually separated from the body message being the header information. Among the email messages in this study, towards $80 \%$ of the messages contain subject lines. The subject lines found in the corpus are split down into three categories according to their content. The first category includes the acceptable subject lines that are appropriate and relevant to the message content. The second category includes improper subject lines that include too long subject lines and/or inaccurate subject lines that are too vague or inappropriate to the content of the email. The third category includes the emails that do not contain subject lines.

As for the first category, postgraduate students try to give their professor an idea about the subject matter of their messages and to appeal his intention. They write a subject line, which is relevant to their communicative goal and to the intended request that they want their professor to achieve. This category accounts for $44.50 \%$ of the whole subject lines used. Some examples of acceptable subject lines are mentioned: "An application form to sign" (email No 4), "about the publication of papers" (Email No. 25), "A Letter of Recommendation" (Email No.88) and "My research proposal" (Email No. 176).

As for the second category of subject lines, the emails writers use either subject lines written improperly such as in sample 77 "asking" or too longue subject lines such as "Hello I hope you are fine, I really want to resume work with you and I want to check if receive my emails, if yes; please send me an email, thanks". (Email No. 5), "I wish you are fine Sir. I am thinking about making an analysis of parliamentary discourse of Tony Blair. That is speeches delivered in parliament about war in Iraq. What do you think of the idea?" (Email No. 29).

Inaccurate subject lines are too vague subject lines that may be the subject line of any email such as "Greetings" (Email No. 41) "Asking for help" (Email No. 44), "Urgent” (Email No. 45) and "Hi” (Email No. 46). Even spam emails may use these types of subject lines. Therefore, the receiver may not be too enthusiastic to read them from the very beginning. The subject lines that are written in French or Arabic are also included in this category such as "Rendez-vous" (Email No. 3) and "Salam" (Email No. 39). It is also noticed that there is a tendency on the part of the subjects to use greetings and address terms such as "Greetings" (Email No. 41) "Hi" (Email No. 46) "Good afternoon sir" (Email No. 141), "Dear sir" (Email No. 104). This category accounts for $35.71 \%$ of the overall emails. Therefore, it was quite difficult to sense the close relation between the subject lines and the topic and the function of messages. Thus, the recipient has to read the whole mail message in order to know the topic of the message.

The third category is devoted to the samples that do not contain subject lines. They are 20 samples (example: $9,12,16,19$, etc.) and account for $20.37 \%$ of the whole corpus. Thus, only $43.4 \%$ of the subject lines found in the corpus are proper and appropriate to the emails written by postgraduate students to their professor while $55.49 \%$ of them are either inappropriate, improper or do not exist 
Table 1. Classification and percentages of subject lines

\begin{tabular}{|l|l|l|l|}
\hline $\begin{array}{l}\text { Acceptable subject } \\
\text { line }\end{array}$ & $\begin{array}{l}\text { Improper subject line (too long, inaccurate or } \\
\text { inappropriate) }\end{array}$ & $\begin{array}{l}\text { With no subject } \\
\text { line }\end{array}$ \\
\hline Total: 81 & Total: 65 & Total:36 \\
\hline Percentage: $44.50 \%$ & Percentage:35.71\% & $\begin{array}{l}\text { Percentage: } \\
19.78 \%\end{array}$ \\
\hline
\end{tabular}

To be considered as acceptable, any subject line should be written in a high level of competence. A general guideline for writing subject lines is to ensure that it is relevant to the content of the mail, and is helpful in that the recipient has a good idea of what the mail is about (Ofulue, 2010, p. 309). Crystal (2006) argues that the subject line should be specific in an email message. It is extremely important to write a functional subject line to give an idea about the message and its importance to the recipients (Munter et al., 2003).

Generic subject lines may be the cause of their deletion or of their sending to the spam box. The subject line plays an important role as having an attention getting from the receiver. The reader will either open the email or discard it from the very beginning after reading the subject line. The subject line should aim to capture the attention of the receiver and thus to urge him/her open the email and read it. Indeed, the subject line is mainly used to reinforce the addresses' interest in reading the email. Therefore, email writers should be careful to choose the appropriate subject line in order to catch the addressee's intention. As it is attested from results, the participants seem to some extent not able to write proper subject lines when it comes to email their professor.

\subsection{Opening formula.}

After elaborating a subject line, the participants have to draw their professor's attention by using the appropriate opening formulas. Roshid (2012) asserts that opening salutation/greeting is an important aspect in email communication. Indeed, discursive elements such as opening formulas play important social roles. It is through the opening stages of any social encounter that the social relation among co-participants is negotiated and established (Bou Franch, 2006). Guffey (2010) asserts that beginning an email message with a proper greeting is important because it shows friendliness and indicates the beginning of the interaction. Greetings and leave-taking moves are generally considered as "the most salient structural features of an email" (Pérez Sabater et al., 2008; p. 76).

In this study, only the greeting move is taken into consideration for analysis as being a representative move of openings. The greeting move is used as an umbrella term to include salutations, terms of address and greetings. In most cases, the presence or absence of a greeting in the opening and the type of greetings sets the tone for the interaction that follows, whether in face-to face or CMC communication (Chiluwa, 2010). Furthermore, greetings not only perform the essential function of constructing politeness, it also sets the pace for future communications (Chiluwa, 2010). The greeting was often the first move in the message and it usually included a formal or informal formula followed by a direct address of the receiver (BouFranch, 2006).

In the current study, the opening formulas are split down into three categories. The first category includes the acceptable and appropriate openers, which are formal. The second category includes the inappropriate openings, which are improper or informal openings while the third one is devoted to the emails that do contain any opener. It is found that $60.4 \%$ of the examined emails use acceptable openings. They contain phrases such as "Dear Prof ", "Hello sir", "dear professor" and "dear supervisor" which were considered to function as distancing mechanisms oriented towards deference, independence, distance and a show of respect (Brown and levinson, 1987; Chiluwa, 2010; Scollon and Scollon, 1995; Waldvogel, 2007).

Since social and professional titles generally reflect social achievements, acknowledging them is viewed as a way of showing respect to the addressee (Chiluwa, 2010). The formal greetings are discourse patterns oriented to the expression of independence, deference and respect. More specifically, the use of formal greetings and use of receiver's surname emphasize the formality and distance between the email's sender and receiver. Traditional titles in particular are a form of identification with the addressee's prestige and social roles (Chiluwa, 2010). The findings reveal that the participants use the name of their supervisor when opening the email message such as in "Dear professor + Last Name", "Dear Mr + Last Name", "Dear professor+ Full Name". The use of formal forms of address is achieved through the use of honorific (HON) or 'title + last name'.

Using formal address forms may be used deliberately as recognition of the addressee's status and social position. Thus, this serves as means to give the recipient the kind of address form he desires. On the other hand, phrases such as "hi", "Hi sir+ First name+(-)", are considered informal since they express closeness, involvement and familiarity. Informality is achieved either through an informal phrase such as "hi" or through using the first name instead of the surname. Such phrases show a sense of informality and are common in interactions among friends, social equals and people of the same age group (Chiluwa, 2010).

Politeness cues used in openings generally reflect the user's interest in the addressee's needs which narrows social distance and provides closer socio-interpersonal space for interaction (Brown and Levinson, 1987). Ingroup identity markers such as informal greeting and use of the supervisor's first name underlie the apparent 
familiarity between the interlocutors. Indeed, using a supervisor first name may reduce the distance. The existence of first name in a message is usually in line with a conversational and informal tone demonstrating a close and friendly relation with the recipient such as in "Hi + First Name". Therefore, the use of personal names has the tendency to reduce the level of distance and increase solidarity and closeness (Chiluwa, 2010). Greeting is considered as a medium by which the speaker or writer constructs his or her social and professional identity and relationship with the addressee (Waldwogel, 2007). Thus, the greeting is a move of great social significance, since, through it, the participant shows an interest in the receiver, begins to seek common ground and decides on the degree of politeness to be used (Bou Franch, 2006).

The inclusion of emoticons in openings may be considered as a sign breeching the social norms in an academic setting. Emoticons are usually used in much more close relationship rather than in a supervisorsupervisee or student-professor communication. In the present corpus, however, a tiny number of emoticons was used. To achieve their intended goals, the participants deliberately use informal address forms and greetings and in few cases emoticons to minimize the distance between them and their supervisor or professor and establish a comfortable atmosphere of interaction. Results revealed that $31.31 \%$ of the opening formulas are informal. However, in line with Hallajian and Khemlani (2014), in a student-faculty relationship, a failure to employ a suitable form of address is considered as impolite or a sign of breaching social norms, thus, Tunisian postgraduate students are supposed to construct more formal emails.

On the other hand, results reveal that 15 cases, which represent $8.25 \%$ of the entire corpus, do not use any kind of opening formula. Gains (1999) asserts that when the addressee is unknown to the addresser, the use of opening formulas in emails is not mandatory. In his study, he found that $92 \%$ of commercial emails contained no openings at all. However, in the current study, the addressee is either the supervisor of the participants or their professor. Therefore, greeting formulas should not be ignored

In sum, the most common discourse patterns in the opening sequences were oriented towards the expression of deference, independence, distance and a show of respect. It seems that Tunisian postgraduate give much importance to social roles. This can be explained by the fact that Tunisian students have a tendency to address their professor in a polite way. This is the typical social relation between students and their professor.

Table 2. Number of occurrence and percentages of Opening sequences

\begin{tabular}{|l|l|l|}
\hline Opening sequences & Number of occurrence & Frequency \\
\hline Salutation move & 114 & $62.63 \%$ \\
\hline Greeting move & 59 & $32.41 \%$ \\
\hline Self-identification move & 27 & $14.83 \%$ \\
\hline Phatic communication move & 52 & $28.57 \%$ \\
\hline
\end{tabular}

\subsection{Body text.}

In addition to the subject line and the opening formulae, the body of any email remains important as it bears the whole message. Indeed, it is difficult to ascribe a structure to the message body of all the collected emails but a tentative generalization is made. By examining the structure of the gathered emails, it is noticed that postgraduate students tended to use the inductive style when emailing their supervisor or professor. They do not go straight to the request. Instead, they go through some strategies until expressing their request to their professor. These strategies are classified as follows:

4.3.1. Introduction.

The messages vary to some extent in length but almost all of them start with an introduction. In order to appear polite and show respect to their professor, most of Tunisian postgraduate students elaborate an introduction in their emails in which they ask about his health and his well-being (E.gs. "How are you? I hope you're doing well" (Email No 3); "I am writing to ask about your health hoping you are in the best conditions" (Email No 8).

They even sometimes ask about the health of his family members even though they do not know them (E.gs: "How are you and how is your family? I wish you are enjoying the holidays well". (Email No. 89"); "I hope this message finds you and your family well". (Email No 163)). This strategy may come as a result of Tunisian cultural traditions since when Tunisian people communicate face -to-face or by phone, they usually start their conversations by greeting and asking about the health of each other and their family members. In the Tunisian culture, saying greetings is considered very important. Thus, this could be considered as an instance of transfer of Tunisian communicative strategy to the English language.

However, this strategy could be not fruitful as it may take up the professor's time to read the introduction before getting straight to the point. In addition, in some emails, the writers express their best wishes to their professor in the occasion of a 'New Year', or religious occasion to show their respect and politeness and it may aims at invoking compassion (E.gs.: "I want to wish you Happy Aid" (Email No. 180), "Warm greetings and happy new year" (Email No. 160), "Dear Prof + Last name, I hope that my message finds you in the best of your health. I'd like also to wish you a happy and blessed Ramadan, May Allah accept from you and from us. Ameen" (Email No 123). 


\subsubsection{Self-identification.}

Results reveal that 27 emails started with a self-identification move by which the subjects let their supervisor or professor remember them and refresh his memory. These introductory statements serve to identify the email writer. When introducing oneself to their interlocutor, the participants often shed light on their academic background and professional affiliation.

Example 1: "I am your student X. You already know me. You were a member of the jury in the defense of my thesis which was under the supervision of Mr Y. I came to your office and showed you my research proposal of my PhD thesis concerned with the automatic translation" (Email No 18).

Example 2: "Sir, I'm one of the master's students (ancient regime) and I'm one of the students supervised by you my topic is "teaching a foreign language as a process of acculturation" (Email No 23).

Self-identification is often accompanied with a story-telling approach. Some postgraduate students provide a relatively short narrative in which they narrate some personal stories to their professor. The following examples are illustrations.

Example 1: "I would like to tell you that I suffered bad conditions with my ex-wife during the period of my absence from the field of research. I divorced and I have married again and now my wife and I are expecting a baby. I feel happy and my new conjugal conditions have infused some load of enthusiasm in me to pursue my research" (Email No 8).

Example 2: "This delay was out of my daughter illness, I was about to lose her forever, I have experienced horrible days praying God to protect her. She was in hospital because of highly elevated temperature" (Email No 10).

It is worthy to mention that narrativity is an important feature in communication. Heyd (2008) asserts that narrativity is an elementary quality of human discourse as it is tied to humans' social origin (p. 157). Chiluwa (2010) points out that narrativity is neither a new phenomenon nor strange in computer-mediated communication.

Tunisian postgraduate students rely on 'tellability', which is a feature of narrative discourse. They use relatively long stretches of discourse devoted to narrate their personal details. Their aim is to share their experiences and stories with their professor to ensure closeness and sharing. Dautenhahn (2004) notes that it is an efficient means of 'social grooming' that maintains group coherence. In narrating these stories, the students want their professor to have an idea about some personal details in order to show closeness and prepare the ground for the kind of request that the recipient is expected to take part in.

4.3.3. Apology or reminding remarks.

Another move used by postgraduate students in their body messages is to start their emails by apologizing for their infrequent meeting or inability to finish their theses or parts of it due to some causes that they try to explain. This apology strategy may be used to mitigate the face-threatening act of the request and to ensure the professor's consideration for the request. Egs: "I'm sorry that it's been so long since we've been in touch." (Email No 3); "First of all, I would like to express my sincere apology for being late to report on my latest draft" (Email No. 32).

Apology was a preferred formula for the participants since it represents a means of mitigating the facethreatening effect of the request. The frequent use of apology by the subjects can be explained by the power difference, which is embedded in the interlocutors' social status since the occupational title of the recipient is a professor and is in many cases the addressers' supervisor. This preferred formula may be caused by L1 transfer effect since from a Tunisian speaker's standpoint making a request to someone in authority may impose heavier psychological burdens than making a request to someone of lower status. It is frequent in Tunisian conversations to apologize from higher-ranking subjects when requesting something or some information, especially when the imposition of the request is high.

On the other hand, some emails display some kind of reminding remarks to the recipient to remind him that they previously asked about something but he has not answered them yet. So, they rewrite to him to repeat their request another time.

E.gs: "Just a little reminder about the fax that I haven't received yet. (Email No. 114) "I sent you my doctoral proposal about 3 weeks ago. Is there a hope I'll do it with you?” (Email No. 131).

4.3.4. Pre-request

Another move in the email messages is a pre-request by which the subjects provide their specific purposes. This part prepares the ground for the request. The subjects provided relatively lengthy or contextual information explaining why they needed the request to ask for it and finally they placed the request act or purpose statement at the end of the message.

E.gs: "I need it urgently because there is a deadline to deposit my papers in the University of Gafsa" (Email 21). "I need to meet you for this matter mainly that I need a letter of support from you to confirm funding from Sfax, Manouba as well as 9 Avril” (Email No 71).

4.3.5. Request

After stating the prelude, the emails writers state their request. Indeed the last part of the message is devoted to 
provide the request move.

Example 1: "I kindly wonder if there is any possibility you administer the proofreading of my work by you or any qualified person that you can recommend" (Email No. 107).

Example 2: "Pls do your best and send me a word." (Email No. 112)

In fact, it is worthy to note that not all requests are placed at the end of the message. It is found that some requests are sometimes placed at the beginning of the message, this always happens when the email message is short. Indeed, resorting to the inductive approach is intentionally chosen for the sake of indirectness. The participants may not feel comfortable when they mention their communicative purpose and request at the beginning. This may be due to the fact that requests are face threatening acts by nature. The participants gradually steer their request in order to let their professor be prepared for the ensuing request and not to get a request abruptly. The use of the inductive approach to structure emails and the delayed purpose statement may be considered as a common cultural practice for Tunisians in making requests. Tunisians always present introductions and pre-request information in their conversations instead of going straight to the request that they want from their addressees. This reflects the influence of Tunisian cultural norms and thus the imprint of native cultural practice.

Such an inductive approach, however, is likely to be viewed as "an ineffective discourse structure by those working in an institutional context where e-mails are often read quickly" (Chen, 2006, p. 42). As Crystal (2001, p. 109) notes "an e-mail writer should assume that information located at the end of the message might never be seen, if the reader decided not to scroll down any further". Thus, it is probably more effective to structure an email message in a deductive approach; that is to place the most important information or the purpose at the beginning as many email writing books (eg. Booher, 2001; Flynn and Flynn, 2003) recommend.

\subsection{Closings/signing off.}

In the current study, closing is the final component of email messages. Closings re-establish the interpersonal relationship between students and their teacher. Closing sequences indicate the transition from a state of communication to the one of non-communication. Emails end with closings and signing off expressions since addressers wait for the addressees' reply. It is assumed that closing interactions in socially appropriate, frictionless ways is usually seen as negotiated accomplishments related to face and interactional organization (Schegloff and Sacks, 1973, Albert and Kessler, 1978 cited in Bou-Franch, 2006). Waldwogel (2007, p. 467) points out that signing off or adding a closing to a message is also a way of doing deference or signaling respect and thus constructing the addressee as having status. Closings cannot be done abruptly and email senders do facework and organizational work to achieve closing successfully, and they also take into account the receiver to achieve this closing smoothly (Hallajian and David, 2014).

In this part of analysis, only signatures and leave-taking moves are taken into consideration since they are representative. Other closing moves such as thanking and/or apologizing moves are not taken into consideration. The closing formulas found in the corpus under examination are classified into three categories. The first category includes the closing formulas, which are considered acceptable since they contain both greetings and the sender's name. They account for $41.2 \%$ of the examined emails, for example "Best regards, full name", "All the best + first name" and "Yours gratefully + full name". These examples show a high degree of formality and realize positive politeness strategies.

Address information is probably the most typical element of a user signature to be automatically attached to the bottom of an email (Heyd, 2008, p. 62) that is why it is found that postgraduate students sometimes end with personal signatures using their proper names and the name of the institutions they belong to. In several emails, the writers give much more contact details such as the telephone number, the name of the institution, email address, etc. for further details for the sake of contact as it is the case in email number 1 :

\section{"Full name}

Lecturer in English and Applied Linguistics

University of Gabes

The Higher Institute of Applied Studies in Humanities at Medenine, Tunisia

Route Ben Guerdane - B.P. $n^{\circ} 91$ - 4100 Medenine

Phone:

Fax :

Mobile phone :

Email : @yahoo.fr»

It is worthy to note that there is a tendency on the part of the participants to use formal closings such as "best regards, all the best, yours faithfully". In line with Chiluwa (2010), this can be considered as common forms of constructing status and social distance that is attributable to the traditional view of politeness. The second category of closings is devoted to the improper or incomplete closing sequences. Incomplete closings either do not contain greeting or do not contain the sender's name. Results reveal that 52 emails $(28.57 \%)$ 
contain improper or incomplete closings such as full name (Email No. 8), your sincerely (Email No. 15), yours, (Email No. 19).

The third category is devoted to the emails that do not contain closing remarks. There are 55 emails $(30.25 \%)$ that do not include closings. Thus, as it is clear from table 3 below, more than half of the emails (58.78\%) either do not display perfect closings or do not display closings. According to Hatch (1992), the sender of an electronic message has to generate a closing. Hence, it is suggested that Tunisian students should understand that openings and closings have a great influence on the recipients of emails and therefore they should open and close their email messages in an appropriate way.

Table 3. Number of Occurrence and percentages of closing sequences

\begin{tabular}{|l|c|c|c|}
\hline \multicolumn{3}{|c|}{ Closing sequences } \\
\hline & $\begin{array}{l}\text { Pre-closing (thanking and/or apologizing) } \\
\text { move }\end{array}$ & Leave taking move & Signature move \\
\hline $\begin{array}{l}\text { Number of } \\
\text { occurrence }\end{array}$ & 87 & 95 & 106 \\
\hline Frequency & $47.80 \%$ & $52.19 \%$ & $58.24 \%$ \\
\hline
\end{tabular}

\section{Conclusion and implications}

In the present study, the structural organization of requestive academic emails written by Tunisian postgraduate students was examined. The analysis of email component moves reflects the generic and pragmatic flaws that govern the rhetorical construction of email messages by Tunisian postgraduate students. The discourse structure of the emails written by Tunisian postgraduate students to their professor was analyzed following Swales (1990) and Guffey (2010) frameworks. The gathered emails are made up of the email's subject line, an opening (salutations and alerters), body text and closing.

The findings revealed that more than half of the subject lines of emails either inappropriate, improper or do not exist. This shows that the participants are to some extent not able to write proper subject lines when addressing their professor. As far as openings are concerned, it is found that Tunisian postgraduate students in this study did appear to pay attention to greetings in their emails. The great variation in openings styles in the data reveals that there is no common expectation and standards pertaining to the style of writing among the respondents. Tunisian postgraduate students employ both formal and informal openings. The study related the discourse practices in the opening moves to their interpersonal meanings broadly divided into expressions on the one hand of familiarity, involvement and closeness - rapport-building actions (positive politeness) and on the other hand expressions of distance, independence and deferencerespect building actions (negative politeness) (Brown and Levinson, 1987; Scollon and Scollon, 1995; Spencer-Oatey, 2000).

By examining the structure of the body of the gathered emails, it is noticed that postgraduate students tended to use the inductive style when emailing their professor. They do not go straight to the request. Instead, they go through some strategies until expressing their request to their professor. These strategies are classified as follows: almost all of the emails start with an introduction. In order to appear polite and show respect to their professor, Tunisian postgraduate students elaborate an introduction in their emails in which they ask about the health of their professor and his well-being. This strategy could be considered as transfer of Tunisian communicative strategy to the English language. However, this strategy could not be fruitful as it may take up the professor's time to read the introduction before getting straight to the point.

Results reveal that some emails started with a self-identification strategy by which the subjects let their supervisor remember them and refresh his memory. These introductory statements serve to identify the email writer. This is often accompanied by a story-telling approach. Some postgraduate students provide a relatively short narrative in which they narrate some personal stories. Another strategy adopted by postgraduate students is to start their emails by apologizing for their infrequent meeting or inability to finish their theses or parts of it due to some causes that they try to explain. This apology strategy may be used to mitigate the face-threatening act of the request and to ensure the professor's consideration for the request. The frequent use of apology by the subjects can be explained by the power difference, which is embedded in the interlocutors' social status since the occupational title of the recipient is a professor and is the addressers' supervisor for many cases. This preferred formula may be caused by L1 transfer effect since from a Tunisian speaker's standpoint making a request to someone in authority may impose heavier psychological burdens than making a request to someone of lower status.

On the other hand, some emails display some kind of reminding remarks to their supervisor or professor to remind him that they previously asked about something but he did not answer them yet. Another part in the 
email message is a pre-request by which the subjects provide their specific purposes. This part prepares the ground for the request. The subjects provided relatively lengthy or contextual information explaining why they needed to make the request and finally they placed the request act or purpose statement at the end of the message. After stating the prelude, the emails writers move to state their request. In fact, it is worthy to note that not all the requests but the majority are placed at the end of the message. Such an inductive approach, however, is likely to be viewed as an ineffective discourse structure by those working in an institutional context where e-mails are often read quickly (Chen, 2006, p. 42).

The final element in the emails is closings, which serves to re-establish the interpersonal relationship between the students and their professor. The findings revealed that more than half of the emails either do not display perfect closings or do not display closings while the remaining emails are considered acceptable since they contain both greeting and the sender's name. Hence, it is suggested that Tunisian students should understand that openings and closings have a great influence on the recipients of emails and therefore they should open and close their email messages in an appropriate way.

The results of this study have some pedagogical implications and seeks to increase the learners' language awareness. This study attempts to provide some potential explanations for the infelicities of writing appropriate emails related to the insufficient exposure to the pragmalinguistic contextualization conventions. It is important to raise nonnative students' awareness to email message conventions in terms of their standard generic components, and their pragmatic functions, as well as the linguistic expressions used to realize them, and how these organization options and linguistic realizations vary according to the social context.

It is argued that unless students are exposed to recent books that explicitly address email use in academia (e.g. Swales and Feak, 2000), or unless ESL/EFL teachers incorporate email composition into their syllabi, students are left to their own devices in trying to craft a message that is effective as well as status-congruent and polite (Chen, 2006). NNs have to make sociopragmatic choices regarding, for example, openings, forms of address and closings, amount of mitigation strategies and the types of modification strategies (EconomidouKogetsidis, 2011).

Accordingly, this study suggests some useful pedagogical implications. Tunisian EFL learners need to be supplemented with explicit instruction regarding the pragmatics of English and specifically teaching pragmatic issues concerning writing emails. This may be achieved by using authentic materials and more classroom awareness-raising activities (Aribi, 2014). The use of authentic materials in the context of pragmatics instruction is highly recommended as it can highly benefit Tunisian EFL learners to raise their awareness about pragmatic issues such as politeness. Another practical method is to introduce and teach email writing guidelines and etiquettes so that Tunisian students can readily refer to them when writing emails. Teachers can also help students understand academic email etiquettes by explicitly explaining what they expect in the student email. In line with Bolkan and Holmgren (2012), professors may explain email policies or put the email guidelines in their course syllabi.

\section{References}

Al-Ali, M. and Alawneh, R. (2010). Linguistic mitigating devices in American and Jordanian students requests. Intercultural Pragmatics, 7, 311-339.

Al-Ali, M. N. \& Sahawneh, M. (2008) 'An investigation into the generic features of English requestive e-mail messages, Language for Specific Purposes (LSP) \& Professional Communication, 8 (2): 40- 65.

Albert, S., and Kessler, S. (1978). Ending social encounters. Journal of Experimental Social Psychology,14, 541553.

Al-Khatib, M. (2001). The pragmatics of letter-writing. World Englishes, 20, 179-200.

Al-Khatib, M. (2008). E-mails as a mode of Communication among Jordanian University Students: A Sociolinguistic Perspective. The International Journal of Language Society and Culture, 25, 1-17.

Aribi, I. (2014). Analysis of the speech act of request in EFL materials. International Journal of Learning and Teaching, 6, 13-29.

Bhatia, V. (1993) Analyzing Genre: Language Use in Professional Settings.

Biesenbach-Lucas, S. (2006a). Making requests in email: Do cyber-consultations entail directness? Toward conventions in a new medium. In K. Bardovi-Harlig, J. C. Félix-Brasdefer, \& A. Omar (Eds.), Pragmatics and language learning (pp. 81-108). Honolulu, HI: Second Language Teaching and Curriculum Center, University of Hawaii.

Biesenbach-Lucas, S. (2007). Students writing emails to faculty: An examination of e-politeness among native and non-native speakers of English. Language Learning and Technology, 11, 59-81.

Bloch, J. (2002). Student/teacher interaction via email: The social context of Internet discourse. Journal of Second Language Writing, 11, 117-134.

Bolkan and Holmgren (2012),

Booher, D. (2001). E-writing: 21st-century tools for effective communication. New York: Pocket Books. 
Bou-Franch, P. (2006). Solidarity and deference in Spanish computer-mediated communication: a discoursepragmatic analysis of students' emails to lecturers. In: Bou-Franch, P. (Eds.). Ways into Discourse. Comares, Granada, (pp. 61-79).

Brown , P. \& Levinson, S. (1987). Politeness: Some universals in language usage. Cambridge, MA: Cambridge University Press.

Chen, C-F.E. (2006).The development of e-mail literacy: From writing to peers to writing to authority figures. Language Learning and Technology, 10, 35-55.

Chiluwa, I. (2010). Nigerian English in email informal messages. English World-Wide, 31, 40-61.

Chiluwa, I. (2010). The Pragmatics of Hoax Email Business. Proposals Linguistik online 43, 3/10 Communication, Case Western Reserve University, USA .Sprouts: Working Papers on Corney, 2003).

College English, 55(6), 626-43.

Crystal, D. (2001). Language and the Internet. Cambridge, Cambridge University Press. http://dx.doi.org/10.1017/CBO9781139164771

Crystal, D. (2001). Language and the Internet. Cambridge, Cambridge University Press. http://dx.doi.org/10.1017/CBO9781139164771

Crystal, D. (2006). Language and the Internet (2nd Eds.). Cambridge: Cambridge University. http://dx.doi.org/10.1017/CBO9780511487002

Crystal, D. (2006). Language and the Internet (2nd Eds.). Cambridge: Cambridge University. http://dx.doi.org/10.1017/CBO9780511487002

Economidou-Kogetsidis, M. (2011). Please answer me as soon as possible: Pragmatic failure in non-native speakers' e-mail requests to faculty. Journal of Pragmatics, 43, 3193-3215.

Epstein, D. (2006). Be polite, e-polite. Inside Higher (Eds.). Retrieved April 4, 2008, from http://insidehighered.com/ news/2006/04/19/Oregon.

Flynn, N. \& Flynn, T. (2003). Writing effective e-mail: Improving your electronic communication. Menlo Park, CA: Crisp Publications.

Gains, J. (1999). Electronic Mail-A New Style of Communication or Just a New Medium? An Investigation into the Text Features of E-mail'. English for Specific Purposes, 18, 81-101.

Georgakopoulou, A. (2003). Computer-mediated communication. In: J. Verschueren, J-O. Östman, J. Blommaert, and C. Bulcaen (Eds.). Handbook of Pragmatics (2003). Amsterdam/Philadelphia, John Benjamins.

Glater, J. D. (2006). To: Professor@Univeresity.edu subject: Why it's all about me. The New York Times. Retrieved from http://www.nytimes.com/2006/02/21/education/21 professors.html

Guffey, M. E. (2010). Essentials of business communication (Eighth Eds.). Mason, OH: SouthWestern Cengage learning.

Hallajian, A. and David, M. K. (2014). Hello and good day to you dear Dr' Greetings and closings in Supervisors-Supervisees Email Exchanges . Procedia - Social and Behavioral Sciences, 118, 85 - 93.

Halpern, J. (1985). An electronic Odyssey. In L. Odell and D. Goswami (Eds.).

Hartford, B. S. and Bardovi-Harlig, K. (1996). "At your earliest convenience:" A study of written student requests to faculty. In L. F. Bouton (Eds.). Pragmatics and Language Learning, Monograph Series, Vol. 7 (pp. 55-69). Urbana Champaign, IL: University of Illinois, Division of English as an International Language (DEIL).

Hawisher, G. and Moran, C. (1993) Electronic mail and the writing instructor.

Heyd, T. (2008). Email Hoaxes. Amsterdam, Philadelphia.

Herring, S. (1996a). Computer-mediated communication: Linguistic, social, and cross-cultural perspectives. Amsterdam, John Benjamins.

Herring, S. C. (2001). Computer-Mediated Discourse. To appear in the Handbook of Discourse Analysis, edited by Deborah Tannen, Deborah Schiffrin, and Heidi Hamilton. Oxford: Blackwell.

Lan, L. (2000). Email. A Challenge to Standard English? English Today, 16, 23-29.

Lea, M. (1991). Rationalist assumptions in cross-media comparisons of computer mediated communication. Behaviour and Information Technology, 10, 153-172.

London: Longman.

Lund, C.A. (1998). The presence of others: Voice, audience, and e-mail. Available on-line at: http:// leahi.kcc.hawaii.edu.edu.org.icon98/paper lund.htm

Mail. Santa Monica: The Rand Corporation.

Martin, M. M., Myers, S. A., and Mottet, T. P. (1999). Students motives for communicating with their instructors. Communication Education, 48, 157-164.

Munter, M. (2003). Guide to Managerial Communication. Effective Business Writing and Speaking. Upper Saddle River, Prentice Hall.

Ofulue, C. (2010). Advance Fee Fraud (419) Scams: A Digital Forensic Analysis. In R. Taiwo (Eds.). Handbook of Research on Discourse Behaviour and Digital Communication: Language Structures and Social 
Interaction. Philadelphia, Pa : IGI Publishers. pp. 296-317.

Pérez Sabater, C., Turney, E. and Montero Fleta, B. (2008). Orality and Literacy, Formality and Informality in Email Communication. Ibérica, 15, 71-88.

Roshid, M. M. (2012). What makes e-mail communication effective? A discourse analysis in an international business sector. Paper presented in the International Conference "ICT for Language Learning".

Schegloff, E. A. and Sacks, H. (1973).Opening Up Closings. Semiotica, 8, 289-327.

Scollon, R. and Scollon, S. (1995). Intercultural Communication. Cambridge, MA: Blackwell.Scollon, R. and Scollon, S.W. (2001[1995]). Intercultural Communication: A Discourse Approach, Malden, MA: Blackwell Publishing Academic Press.

Shapiro, N. and Anderson, R. (1985) Toward an Ethics and Etiquette for Electronic

Spears, R., and Lea, M. (1992). Social influence and the influence of the "social" in computer-mediated communication.In M. Lea (Eds.), Contexts of computer-mediated communication (pp. 30-65). London, Harvester Wheatsheaf.

Spencer-Oatey, H. (2000a). Culturally Speaking: Managing Rapport through Talk across Cultures. Continuum, London.

Spencer-Oatey, H. (2000b). Rapport management: a framework for analysis. In: Spencer-Oatey, H. (Eds.). Culturally Speaking: Managing Rapport through Talk across Cultures. Continuum, London, pp.11-46.

Swales, J. M. (1990). Genre Analysis. Cambridge, Cambridge University Press.

Swales, J. M., and Feak, C. B. (2000). English in today's research world: A writing guide. University of Michigan Press.

Waldvogel, J. (2007). Greetings and closings in workplace email. Journal of Computer-Mediated Communication, 12, article 6 . In: http://jemc.indiana.edu/vol12/.

Wei Hong- Ko, S, Eslami, Z. R., and Burlbaw, L. M. ( 2015). Investigating non-native English speaking graduate students' pragmatic development in requestive emails. International Journal of Society, Culture and Language, 3, 1-15. Writing in Nonacademic Settings (pp. 157-201). New York: Guilford. 